\title{
Burn Injury Induces Proinflammatory Plasma Extracellular Vesicles That Associate with Length of Hospital Stay in Women: CRP and SAA1 as Potential Prognostic Indicators
}

\author{
Robert Maile ${ }^{1,+}$, Micah L. Willis ${ }^{2,+}{ }^{+}$, Laura E. Herring ${ }^{3}$, Alex Prevatte ${ }^{3}$, Cressida Mahung ${ }^{4}$, Bruce Cairns ${ }^{1}$, \\ Shannon Wallet ${ }^{5}$ and Leon G. Coleman, Jr. ${ }^{6, *}$
}

1 Curriculum in Toxicology and Environmental Medicine, North Carolina Jaycee Burn Center, Department of Surgery, Microbiology and Immunology, University of North Carolina at Chapel Hill, Chapel Hill, NC 27599, USA; robert_maile@med.unc.edu (R.M.); bruce_cairns@med.unc.edu (B.C.)

2 Curriculum in Toxicology and Environmental Medicine, University of North Carolina at Chapel Hill, Chapel Hill, NC 27599, USA; mlatw@unc.edu

3 Department of Pharmacology, School of Medicine, UNC Proteomics Core Facility, University of North Carolina at Chapel Hill, Chapel Hill, NC 27599, USA; laura_herring@med.unc.edu (L.E.H.); alex_prevatte@med.unc.edu (A.P.)

4 North Carolina Jaycee Burn Center, Department of Surgery, University of North Carolina at Chapel Hill, Chapel Hill, NC 27599, USA; cmahung@email.unc.edu

check for updates

Citation: Maile, R.; Willis, M.L.; Herring, L.E.; Prevatte, A.; Mahung, C.; Cairns, B.; Wallet, S.; Coleman, L.G., Jr. Burn Injury Induces Proinflammatory Plasma Extracellular Vesicles That Associate with Length of Hospital Stay in Women: CRP and SAA1 as Potential Prognostic Indicators. Int. J. Mol. Sci. 2021, 22, 10083. https://doi.org/ $10.3390 /$ ijms221810083

Academic Editor: Demetrios A Arvanitis

Received: 22 August 2021

Accepted: 14 September 2021

Published: 18 September 2021

Publisher's Note: MDPI stays neutral with regard to jurisdictional claims in published maps and institutional affiliations.

Copyright: () 2021 by the authors. Licensee MDPI, Basel, Switzerland. This article is an open access article distributed under the terms and conditions of the Creative Commons Attribution (CC BY) license (https:// creativecommons.org/licenses/by/ $4.0 /)$.
5 Department of Microbiology and Immunology, Division of Oral and Craniofacial Health Sciences, Adams School of Dentistry, University of North Carolina at Chapel Hill, Chapel Hill, NC 27599, USA; Shannon_wallet@unc.edu

6 Bowles Center for Alcohol Studies, Department of Pharmacology, School of Medicine, University of North Carolina at Chapel Hill, Chapel Hill, NC 27599, USA

* Correspondence: leon_coleman@med.unc.edu

+ These authors contributed equally.

\begin{abstract}
Severe burn injury is a devastating form of trauma that results in persistent immune dysfunction with associated morbidity and mortality. The underlying drivers of this immune dysfunction remain elusive, and there are no prognostic markers to identify at-risk patients. Extracellular vesicles (EVs) are emerging as drivers of immune dysfunction as well as biomarkers. We investigated if EVs after burn injury promote macrophage activation and assessed if EV contents can predict length of hospital stay. EVs isolated early from mice that received a $20 \%$ total body surface area (TBSA) burn promoted proinflammatory responses in cultured splenic macrophages. Unbiased LC-MS/MS proteomic analysis of early EVs ( $<72 \mathrm{~h}$ post-injury) from mice and humans showed some similarities including enrichment of acute phase response proteins such as CRP and SAA1. Semi-unbiased assessment of early human burn patient EVs found alterations consistent with increased proinflammatory signaling and loss of inhibition of CRP expression. In a sample of 50 patients with large burn injury, EV SAA1 and CRP were correlated with TBSA injury in both sexes and were correlated with length of hospital stay in women. These findings suggest that EVs are drivers of immune responses after burn injury and their content may predict hospital course.
\end{abstract}

Keywords: biomarkers; extracellular vesicles; burn injury; trauma; sepsis

\section{Introduction}

Severe burn injury is a one of the most devastating forms of trauma with over 1.1 million burns each year requiring medical attention in the United States [1-3]. Deaths from burn injury are commonly caused by immune-related sequelae such as pneumonia, organ failure and other opportunistic bacterial infections. Paradoxically, these occur days to weeks after repair of the skin barrier function by surgical skin grafting, implicating chronic immune dysfunction. This persistent dysfunction is largely thought to be a result of severe immune dysregulation that occurs early after injury. In fact, burn injury presents 
as a biphasic systemic immune dysfunction [4]. The acute phase (0-72 h post-injury), also referred to as the burn shock or systemic inflammatory response syndrome (SIRS), results in widespread barrier dysfunction and multiple organ failure. During this immediateearly time period, widespread tissue injury and organ damage results in robust Toll-like receptor (TLR) and cytokine signaling in macrophages (MØ) and neutrophils (NØ) [5-8]. Following the acute phase, most patients enter a late/chronic phase of immunosuppression (1-2 weeks after burn) referred to as the compensatory anti-inflammatory response syndrome (CARS) phase with an increased susceptibility to infection, which if left uncontrolled can cause organ failure and death [4,9]. Early immune activation is thought to cause persistent maladaptation of immune cells leading to the later CARS phase. Thus, factors that are released early could be used to predict risk for future complications. Though there have been numerous studies to assess the immunological dysfunction associated with burn injury, there have yet to be predictive biomarkers that can be used to assess high-risk patients and their outcomes.

Extracellular vesicles (EVs) have emerged as novel mediators of immune dysfunction across several immune pathologies [10-12], including burn injury [5,6,13]. EVs are released from nearly all cell types with their size, concentration, and composition being affected based on pathological conditions. EVs are broadly classified based on their size and biogenesis into three main categories: apoptotic bodies ( $>1 \mu \mathrm{m}$ diameter), microvesicles $(\sim 0.1-1 \mu \mathrm{m})$ and exosomes $(\sim 50-100 \mathrm{~nm})$. There is some overlap in size, cargo, and surface markers among the groups, making precise characterization difficult [14,15]. However, exosomes typically originate from the endosomal system while EVs originate mainly from budding of the cellular membrane $[10,14]$. We previously reported that EVs from burninjury patients contain DAMPs such as HMBG1 that are known to promote sepsis and organ failure $[5,16]$. Others have reported that EV numbers after burn are associated with sepsis and clinical severity and that EVs are bioactive [13,17]. In this work, we investigated whether cargo in EVs isolated early after burn injury is altered and associated with hospital course. We hypothesized that plasma EVs released early after burn injury promote proinflammatory activation of peripheral macrophages and that specific cargo could be identified in these EVs to serve as a biomarker to identify at-risk patients.

In order to test this hypothesis, we used a translational approach (Figure 1). First, we used our preclinical large burn model to test the effect of early post-burn plasma EVs on peripheral splenic macrophages. We then used unbiased proteomic assessments to identify molecular candidates that could be assessed in human burn patients. Next, we moved to human patient samples from the UNC Jaycee Burn Center and performed unbiased proteomic and miRNAomic assessments of plasma EVs from human burn patients to compare their cargo with those found in the mouse. Third, we measured the levels of candidate markers identified from our unbiased assessments in a larger cohort of human burn patients and determined their relationship on patient outcomes, specifically length of hospital stay. This translational approach allowed us to identify two potential biomarkers that have immunomodulatory abilities found in EVs early after burn injury-serum amyloid A1 (SAA1) and C-reactive protein (CRP). 


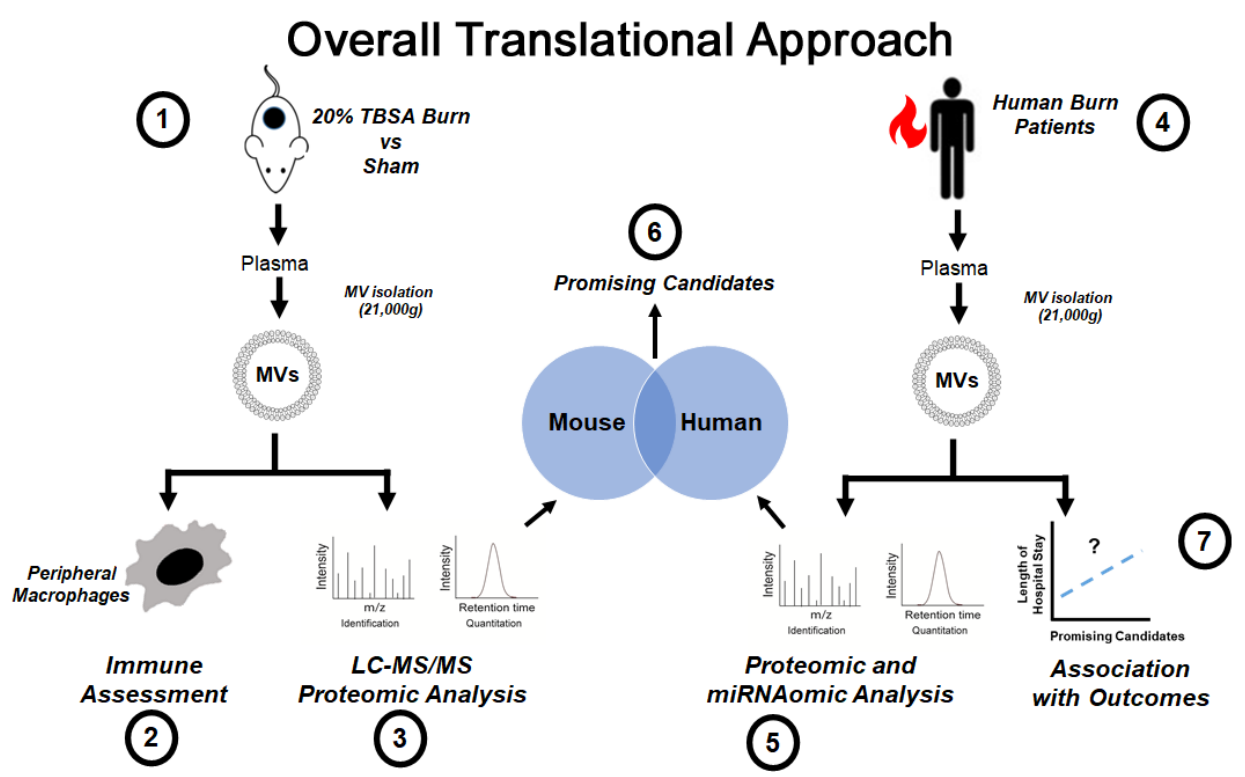

Figure 1. Overall Translational Experimental Design. (1) Mice undergo a 20\% total body surface area (TBSA) burn injury, and EVs isolated within $72 \mathrm{~h}$ after injury. (2) Mouse burn EVs are tested for pro-inflammatory capacity in mouse splenic macrophages. (3) Mouse burn EVs are assessed for protein content using LC-MS/MS proteomic analysis. (4) EVs are isolated from human burn patients with severe burn injury. (5) Proteomic and miRNAomic analysis of human EVs is performed. (6) Proteomic profiles of human and mouse burn EVs are compared, and promising candidates identified. (7) Promising candidates were measured in a larger cohort of human burn patients and associated with length of hospital stay.

\section{Results}

2.1. Plasma EVs from Burn Mice Reproduce Burn-Associated Immune Dysfunction in Cultured Splenic Macrophages

A hallmark of burn injury is profound immune dysregulation, with macrophages being a key compartment impacted $[4,5,7,8,18,19]$, ultimately resulting in susceptibility to infection and mortality. Therefore, we hypothesized burn-derived EVs would significantly alter macrophage responses. Mice underwent a 20\% TBSA cutaneous burn injury ( $n=6$ per group) or sham injury and plasma EVs were isolated three days after injury. EV concentration was similar for EV preparations for each group with diameters between 60-400 $\mu \mathrm{m}$ as measured by nanoparticle tracking analysis (NTA, not shown). EVs from sham or burned mice (sham EV or burn EV, respectively, $3 \times 10^{7}$ per well) were added to primary murine splenic macrophage cultures $\left(1 \times 10^{6}\right.$ cells/well). To define the impact of burn EVs on macrophage function, EVs were added in the presence of LPS, a well-defined pro-inflammatory Gram-negative bacteria-associated molecule. This models the immune environment seen shortly after burn injury where levels of bacterial pathogens are increased due to loss of skin barrier function. After $24 \mathrm{~h}$ of culture, supernatant was assessed for cytokine and chemokine levels by multiplex bead-based ELISA analysis and purified RNA from cell lysates for NanoString multiplex immune gene expression analysis. Compared to sham, burn EVs robustly induced secretion of IL-6 (35-fold, ${ }^{* * *} p<0.001$, Figure 2A), MCP-1 (6-fold, ${ }^{* *} p<0.01$, Figure 2B), IL-12p70 (400-fold, ${ }^{*} p<0.05$, Figure 2C) and IFN $\gamma$ (7-fold, ${ }^{*} p<0.05$, Figure 2D). These cytokines are also found to be increased peripherally early ( 1-3 days) after burn injury in human burn patients and mouse models [4,5,7,8,19-27]. 
A

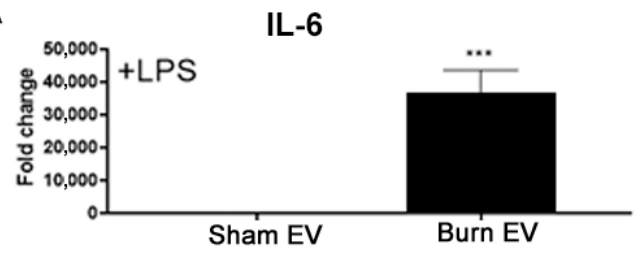

C

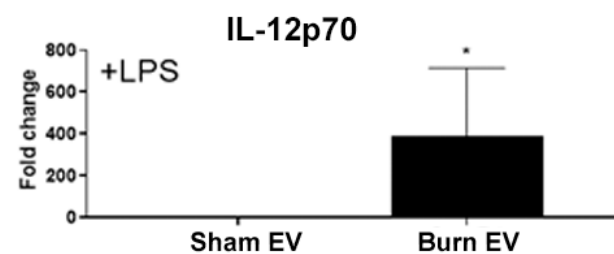

B

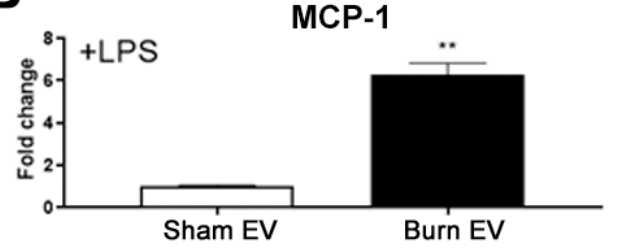

D

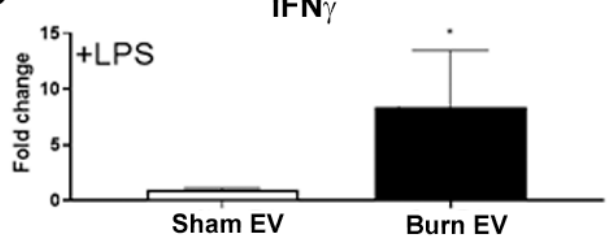

$\mathbf{E}$ Burn vs Sham EV Genes

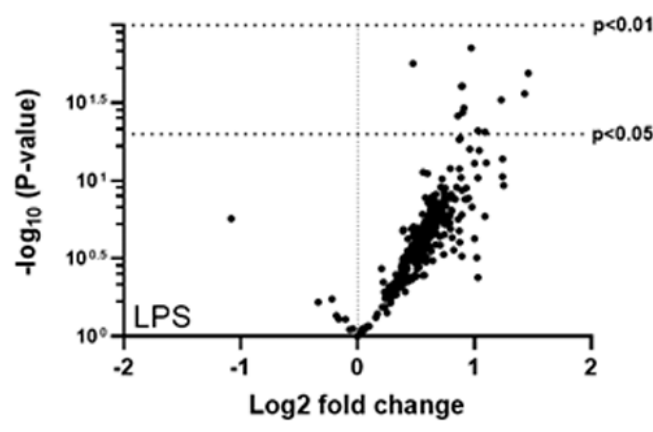

$\mathbf{F}$

Ingenuity Pathway Analysis

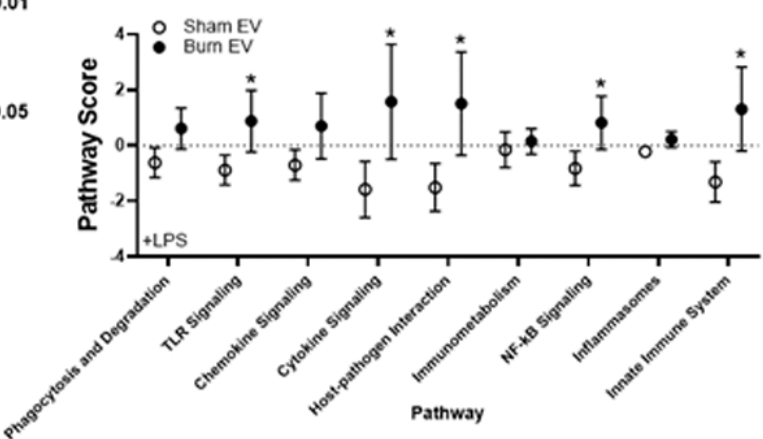

Figure 2. Plasma extracellular vesicles (EVs) after burn injury promote pro-inflammatory signaling in macrophages. Adult mice underwent a $20 \%$ total body surface area (TBSA) burn injury and plasma EVs were collected $48 \mathrm{~h}$ after injury. EVs from burn injury mice (Burn EV) or sham injured mice (Sham EV) were applied ( $3 \times 10^{7} /$ well) to splenic macrophages +/ - LPS (100 ng/mL) for $24 \mathrm{~h}$. (A-D) Media cytokines were measured by multiplex. Burn EVs cause robust increases in pro-inflammatory (A) IL-6, (B) MCP-1, (C) IL-12p70, and (D) IFN : $\tilde{\mathrm{A}}$ in macrophage media. ${ }^{*} p<0.05,{ }^{* *} p<0.01$, ${ }^{* * *} p<0.001$ vs. sham EVs, $t$-test. (E,F) Macrophage lysates were harvested, mRNA isolated, and gene changes measured by NanoString. (E) Volcano plot of several genes significantly induced by burn-EVs relative to sham EVs. (F) nSolver pathway analysis scores of changes in measured immune pathways. Burn EVs significantly altered TLR signaling, cytokine signaling, host-pathogen interactions, NFkB signaling, and the innate immune system in macrophages relative to sham EVs.

For cellular gene expression, we utilized the commercially available Mouse Immunology Panel v3.0 which allows for 561 mRNA general immune genes to be quantified simultaneously. The volcano plot in Figure 2E demonstrates the change in gene expression along with its associated significance, following macrophage exposure to burn EV versus sham EV. Significantly altered genes $(p<0.01)$ are presented in Supplemental Table S1 (data also uploaded to NCBI Gene Expression Omnibus GEO). Principal components analysis (PCA) of this gene expression dataset derived pathway scores (PS), based on the individual gene expression levels for all the measured genes within a specific pathway [28], to identify pathways active in the macrophages. Generally, positive PS indicate pathways which are highly affected based on gene expression patterns observed, while negative PS indicate pathways which are not as affected based on gene expression patterns observed. Figure $2 \mathrm{~F}$ shows the PS driven by EV derived from sham or burn injury. Pathways shown are predicted with $p<0.05$ confidence based on causal gene expression. PS driven by EV after burn injury are generally positive for many key immunological pathways including TLR signaling, phagocytosis, chemokine signaling, etc., compared to the generally negative PS after exposure to sham injury-derived EV. 


\subsection{Large Burn Injury in Mice Alters Plasma EV Proteomic Profile}

Since we found that burn EVs cause significant dysregulation of immune function ex vivo, we began to assess EV protein content. Again, mice underwent a 20\% TBSA burn followed by LC-MS/MS on plasma EVs. EVs primarily in the microvesicle (MV) size range $(0.1-1 \mu \mathrm{m}$ in diameter) were isolated by centrifugation as we have previously reported $[5,29,30]$. LC-MS/MS identified over 700 proteins that were quantifiable, with 53 proteins showing differential levels between burn and control EVs (Table 1). Fifteen proteins were increased in EVs from burned mice compared to 38 proteins that were downregulated after burn injury (Figure $3 \mathrm{~A}$ ). Upregulated proteins fell into five main categories: acute phase proteins (five detected), muscle proteins (four), circulatory/complement proteins (three), protease inhibitors (two) and membrane proteins (one) (Figure 3B). Of the 38 downregulated proteins, the majority were membrane proteins (nine), followed by protein regulators (e.g., proteases, chaperones, five), circulatory/complement proteins (four), cytoskeletal/structural proteins (three), redox reaction regulatory proteins (two), extracellular matrix proteins (ECM, one), and five proteins whose function has not yet been clearly defined (Figure 3C). The largest measured increase was in SAA1 ( 10-fold), an acute phase protein that can modulate innate immune function as a ligand for TLRs. To confirm the LC-MS/MS-detected increase in SAA1, we performed an ELISA which found a comparable 11.5-fold increase in SAA1 in EVs (Figure 3D). A non-significant trend toward a two-fold increase in SAA1 protein in MV-depleted plasma was detected $(p=0.11$, data not shown), indicating the greatest increase in SAA1 protein is within the MV compartment.

Table 1. Differentially expressed proteins in plasma EVs following 20\% TBSA burn injury in mice by LC-MS/MS. Key: LFQ-Label-free quantification.

\begin{tabular}{|c|c|c|}
\hline Gene Name & LFQ Ratio & $p$-Value \\
\hline Haptoglobin $(\mathrm{Hp})$ & 12.0 & 0.003 \\
\hline Serum amyloid A-1 protein (Saa1) & 9.7 & 0.001 \\
\hline Myosin-4 (Myh4) & 7.0 & 0.005 \\
\hline Myosin light chain 1/3 (Myl1) & 6.3 & 0.023 \\
\hline Glycogen phosphorylase (Pygm) & 5.6 & 0.000 \\
\hline Alpha-1-acid glycoprotein 2(Orm2) & 5.0 & 0.014 \\
\hline Serum amyloid A-2 protein (Saa2) & 4.8 & 0.039 \\
\hline Lysophospholipid acyltransferase 5 (Lpcat3) & 3.5 & 0.047 \\
\hline Serum amyloid P-component (Apcs) & 3.0 & 0.000 \\
\hline Complement C1s-B subcomponent (C1sb) & 3.0 & 0.003 \\
\hline Serine protease inhibitor A3N (Serpina3n) & 2.5 & 0.012 \\
\hline Alpha-1-acid glycoprotein 1 (Orm1) & 2.1 & 0.007 \\
\hline Inter-alpha-trypsin inhibitor heavy chain H3 (Itih3) & 2.0 & 0.011 \\
\hline C4b-binding protein $(\mathrm{C} 4 \mathrm{bpa})$ & 1.8 & 0.022 \\
\hline Pyruvate kinase $(\mathrm{Pkm})$ & 1.1 & 0.018 \\
\hline Integrin alpha-IIb (Itga2b) & -1.0 & 0.032 \\
\hline Platelet glycoprotein Ib beta chain (Gp1bb) & -1.1 & 0.009 \\
\hline Gelsolin (Gsn) & -1.1 & 0.011 \\
\hline Integrin-linked protein kinase (Ilk) & -1.2 & 0.023 \\
\hline Cell division control protein 42 homolog (Cdc42) & -1.2 & 0.030 \\
\hline Regulator of G-protein signaling 10 (Rgs10) & -1.2 & 0.037 \\
\hline Beta-parvin (Parvb) & -1.2 & 0.035 \\
\hline Platelet glycoprotein Ib alpha chain (Gp1ba) & -1.2 & 0.044 \\
\hline Lymphocyte antigen 6C1 (Ly6c1) & -1.2 & 0.041 \\
\hline Chloride intracellular channel protein 1 (Clic1) & -1.3 & 0.048 \\
\hline T-complex protein 1 subunit beta (Cct2) & -1.3 & 0.049 \\
\hline Integrin beta-1 (Itgb1) & -1.3 & 0.028 \\
\hline Barrier-to-autointegration factor (Banf1) & -1.4 & 0.008 \\
\hline MOUSE 14-3-3 protein (Ywhah) & -1.5 & 0.011 \\
\hline Translocon-associated protein subunit delta (Ssr4) & -1.6 & 0.027 \\
\hline Syntaxin-11 (Stx11) & -1.7 & 0.045 \\
\hline
\end{tabular}


Table 1. Cont.

\begin{tabular}{ccc}
\hline Gene Name & LFQ Ratio & $p$-Value \\
\hline Cysteine and glycine-rich protein 1 (Csrp1) & -1.7 & 0.043 \\
Calpain small subunit 1 (Capns1) & -1.9 & 0.036 \\
EGF-containing fibulin-like extracellular matrix protein 1 (Efemp1) & -1.9 & 0.016 \\
Phospholipid transfer protein (Pltp) & -2.0 & 0.009 \\
Ras-related protein (Rab21) & -2.0 & 0.039 \\
Leukemia inhibitory factor receptor (Lifr) & -2.3 & 0.011 \\
T-complex protein 1 subunit gamma (Cct3) & -2.4 & 0.037 \\
Retinol dehydrogenase 11 (Rdh11) & -2.5 & 0.021 \\
C-type lectin domain family 11 member A (Clec11a) & -2.6 & 0.035 \\
Transmembrane protein 43 (Tmem43) & -2.6 & 0.021 \\
Choline transporter-like protein 1 (Slc44a1) & -2.8 & 0.044 \\
Ig kappa chain V-V region (1 SV) & -2.9 & 0.025 \\
Calpain-2 catalytic subunit (Capn2) & -3.1 & 0.049 \\
Synaptotagmin-like protein 4 (Syt14) & -3.1 & 0.014 \\
Protein kinase C alpha type (Prkca) & -3.4 & 0.028 \\
Cytoplasmic FMR1-interacting protein 1 (Cyfip1) & -3.5 & 0.030 \\
Tripeptidyl-peptidase 2 (Tpp2) & -3.7 & 0.002 \\
Integrin alpha-L (Itgal) & -3.8 & 0.030 \\
Vomeromodulin (Bpifb9a) & -3.8 & 0.005 \\
Signal peptidase complex subunit 2 (Spcs2) & -3.9 & 0.006 \\
Dimethylaniline monooxygenase (Fmo5) & -4.4 & 0.000 \\
\hline Sodium & -4.4 & 0.007 \\
\hline
\end{tabular}

A

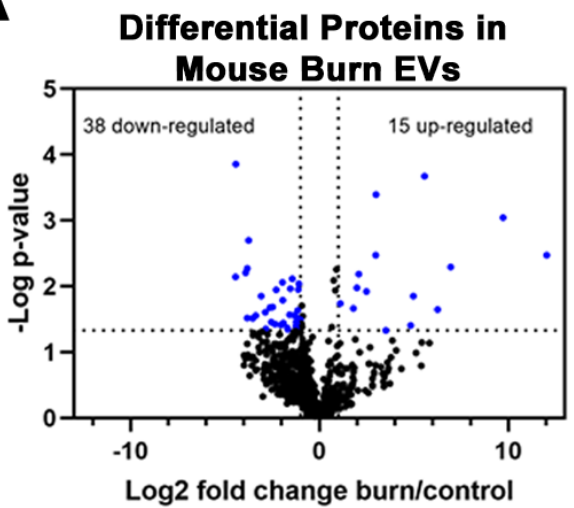

C

\section{Downreguiated Protein Categories in Burn EVs}

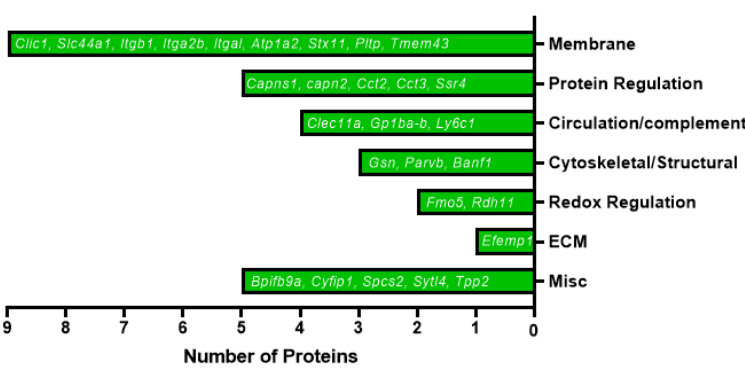

B

\section{Upregulated Protein Categories in Burn EVs}

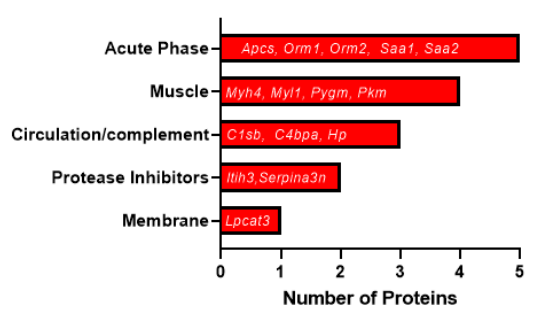

D

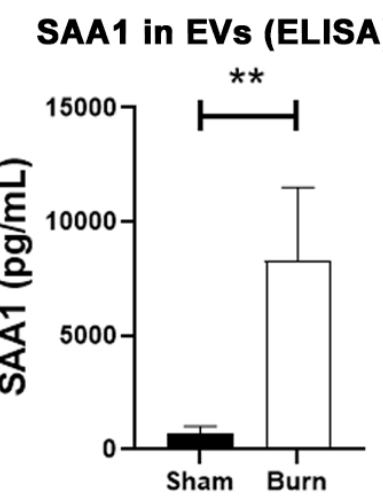

Figure 3. Proteomic changes in mouse plasma EVs after burn injury. Adult mice underwent a $20 \%$ total body surface area (TBSA) burn injury and plasma EVs were collected $72 \mathrm{~h}$ after injury and protein content measured by LC-MS/MS. (A) Differentially expressed protein peptides in burn vs. sham EVs (LFQ ratio, $p$-value Student's $t$-test, $n=3$ per group). (B) Characteristics of proteins that are increased in burn EVs relative to controls. (C) Characteristics of proteins that are decreased in burn EVs relative to controls. (D) ELISA measurement of SAA1 in plasma EVs from sham and burn mice. SAA1 protein was robustly increased in burn-EVs compared to sham. ${ }^{* *} p<0.01, t$-test, $n=4$ sham, 8 burn. 


\subsection{Burn Injury in Humans Alters Proteomic Profile of Plasma EVs with Some Similarities to Mice}

Since several protein changes were found in burn EVs after injury in mice, we performed LC-MS/MS proteomic analysis on plasma EVs isolated from human burn injury patients (>20\% TBSA) within $72 \mathrm{~h}$ of injury. NTA using the Particle Metrix platform found a $52 \%$ increase in plasma EVs in the human burn patients compared to healthy donor controls (Figure 4A). The Particle Metrix machine was able to visualize this increase (Figure 4A, inset). Analysis of the size distributions found the isolated EVs to be primarily in the size range of $100-400 \mu \mathrm{m}$ diameter (Figure $4 \mathrm{~B}$ ), with increased numbers of EVs in this size range in the human burn patients. Using LC-MS/MS, a total of 301 specific proteins were identified, with 23 proteins differentially regulated in burn-injured patients versus healthy controls (Table 2). Sixteen proteins were significantly upregulated while 7 showed reduced expression (Figure 4C). Of the upregulated proteins, the majority were immune-regulating proteins including Fabp5, Iglc6, CD59, CD14, CD44, Lft, and HLA-B (Figure 4D). Three proteins associated with the complement system (Vwf, C5ar1, and F5) were also increased. The largest fold-change increases, similar to findings in the mouse, were in acute phase response proteins CRP and SAA1. Extracellular matrix (ECM) proteins (Reln, Fbln1) as well as musculoskeletal proteins (Prg4) and metabolic regulators (Eno1), were the remaining increased proteins. Downregulated proteins include metabolic regulators (Ahsg and Fetub), immunoglobulins (Igll5 and Ighg3), and cytoskeletal (Acta1) proteins (Figure 4E). There were some systems level similarities between the human burn EVs and the mouse burn model. Particularly, both groups showed robust increases in the acute phase response (APR) protein serum amyloid A-1 (Saa1) as well as an increase in complement cascade proteins (Figure 4F). Notable differences between the two species include a more apparent increase in immune cell-related and extracellular matrix proteins in the humans, while mice showed induction of additional APR proteins and protein inhibitors with a reduction of multiple membrane-associated proteins and protein regulators. Remarkably, although significantly more proteins were measured in the mouse EVs than in humans, a similar percentage of genes was significantly changed in both species $(\sim 7 \%)$. Mice are far more resilient than humans in their recovery from a severe burn injury. Thus, inter-species differences may provide insights into protective factors. Common changes across both species, however, may provide insight into shared mechanistic pathways involved in the response to burn injury. Since EVs carry diverse protein and nucleic acid cargo, we next assessed changes in circulating miRNAs in EVs from human burn patients.

Table 2. Differentially expressed proteins in plasma EVs from human burn patients during the first $72 \mathrm{~h}$ of injury by LC-MS/MS. $n=3$ burn-injured patients, 3 healthy controls. Key: LFQ-Label-free quantification.

\begin{tabular}{ccc}
\hline Gene Name & LFQ Ratio & $p$-Value \\
\hline C-reactive Protein (CRP) & 7.2 & 0.0030 \\
Serum amyloid A-1 (SAA1) & 5.9 & 0.0349 \\
Lactotransferrin (LTF) & 5.8 & 0.0212 \\
HLA class I histocompatibility antigen (HLA-B) & 5.3 & 0.0078 \\
Immunoglobulin lambda constant 6 (IGLC6) & 5.3 & 0.0488 \\
CD59 glycoprotein (CD59) & 4.9 & 0.0388 \\
von Willebrand factor (VWF) & 4.8 & 0.0306 \\
C5a anaphylatoxin chemotactic receptor 1 (C5AR1) & 0.0194 \\
Fatty acid-binding protein, epidermal (FABP5) & 4.8 & 0.0093 \\
Proteoglycan 4 (PRG4) & 4.3 & 0.0387 \\
Monocyte differentiation antigen CD14 (CD14) & 2.8 & 0.0160 \\
Alpha-enolase (ENO1) & 2.7 & 0.0494 \\
Reelin (RELN) & 2.4 & 0.0211 \\
Coagulation factor V (F5) & 2.2 & 0.0075 \\
Fibulin-1 (FBLN1) & 2.2 & 0.0410 \\
CD44 antigen (CD44) & 1.7 & 0.0201 \\
Alpha-2-macroglobulin (A2M) & 1.7 & 0.0246 \\
\end{tabular}


Table 2. Cont.

\begin{tabular}{ccc}
\hline Gene Name & LFQ Ratio & $p$-Value \\
\hline Immunoglobulin lambda-like polypeptide (IGLL5) & -1.5 & 0.0300 \\
Immunoglobulin heavy constant gamma (IGHG3) & -1.7 & 0.0091 \\
Fetuin-B (FETUB) & -2.6 & 0.0340 \\
Actin, alpha skeletal muscle (ACTA1) & -3.2 & 0.0348 \\
Immunoglobulin heavy variable 3-72 OS (IGHV3-72) & -3.3 & 0.0355 \\
\hline
\end{tabular}

\section{A}

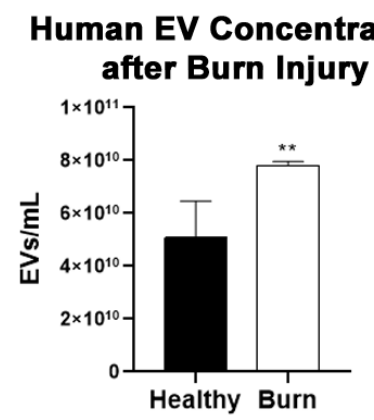

C

\section{Differential Proteins in} Human Burn EVs

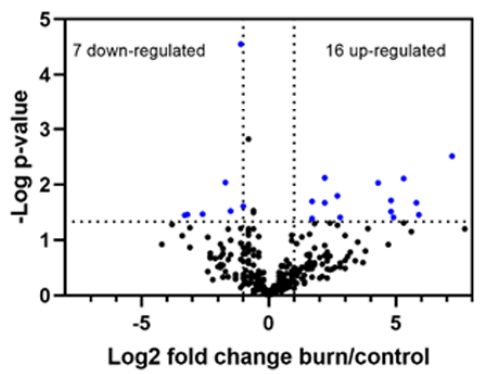

E
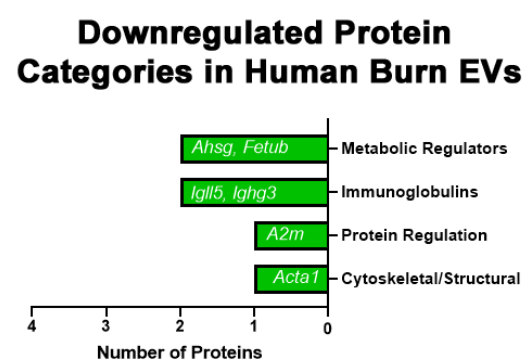

B Human EV Size Distribution after Burn Injury

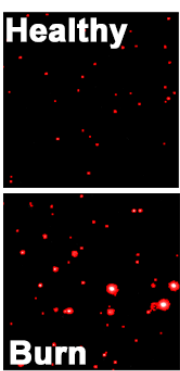

D

\section{Upregulated Protein Categories in Human Burn EVs}

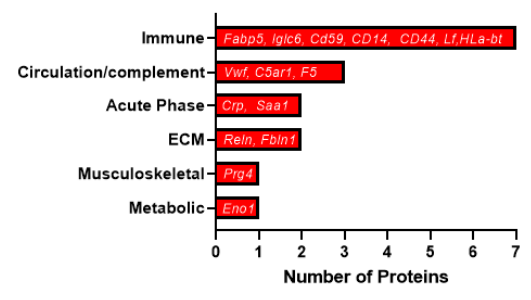

$\mathbf{F}$

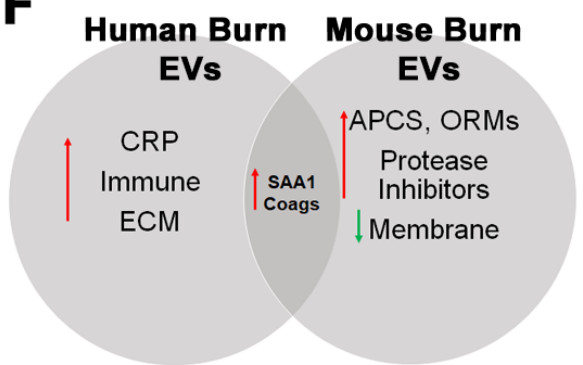

Figure 4. Proteomic changes in human burn patient plasma EVs. Plasma EVs from human burn patients with severe burn injury were isolated within $72 \mathrm{~h}$ of admission. Protein content was measured by LC-MS/MS. (A) EV number was measured by NTA. Human burn patients showed an increase in circulating plasma EVs compared to healthy donors. ${ }^{* *} p<0.01$, $n=3$ /group. Inset shows representative images of EVs captured by the ParticleMetrix ${ }^{\mathrm{TM}}$ machine. (B) NTA size analysis shows the majority of EVs are in the 100-400 $\mu$ m diameter size range, with burn EVs showing increased numbers in the MV size range. (C) Differentially expressed protein peptides in burn vs. healthy donor EVs (LFQ ratio, $p$-value Student's $t$-test, $n=3$ per group). (D) Characteristics of proteins that are increased in burn EVs relative to healthy individuals. (E) Characteristics of proteins that are decreased in burn EVs relative to healthy individuals. (F) Comparison of robust changes between human burn and mouse burn EVs. Both SAA1 and coagulation proteins were increased across species.

\subsection{Burn Injury in Humans Alters miRNAs in Plasma EVs}

In addition to their protein cargo, EVs contain a diverse profile of miRNAs that have been used in a various disease settings such as pancreatic cancer in attempts to identify potential biomarkers [31]. Therefore, we isolated miRNAs in plasma EVs from 
the same patients that were assessed for protein changes by LC-MS/MS using the human miRNA panel v2. The expression of 800 miRNAs relative to healthy control subjects was measured. This analysis identified 26 miRNAs (Figure 5A) that were differentially expressed, four of which showed increased expression (miR-663a, miR-363, miR-4435, and miR519e) while 22 miRNAs showed reduced expression compared to healthy controls (miR-505, miR-671, miR-151b, miR-577, miR-431, miR-409, miR-1224, miR-575, miR-4425, miR-320b, miR-202, miR-338, miR-605, miR-520f, miR-342, miR-651, miR-1180, miR-211, let-7d, miR-1910, miR-18b, and miR-1197). These miRNAs have several known functions. By performing a comprehensive literature search (Table S1) as well as prediction analysis of miRNA targets using TargetScan, we found three main relevant regulatory categories were altered (Figure 5B), including the regulation of inflammation (11 miRNAs), regulation of the APR protein CRP (five miRNAs), and regulation of metabolism (four miRNAs). Interestingly, the directionality of the changes in miRNA was consistent with expected systems level functional changes seen with burn injury. For instance, the expression of several miRNAs that are known to limit proinflammatory responses was reduced (miR 505-3p, miR 671, miR 577, miR 1224, miR 320b, miR 605, miR 342, miR 1180, and miR 211). However, five miRNAs previously found to lower the expression of CRP, were found to be increased. Thus, EV miRNAs might have functional roles in regulating burn-associated protein changes and may also be used as proxies for identifying altered biological systems.
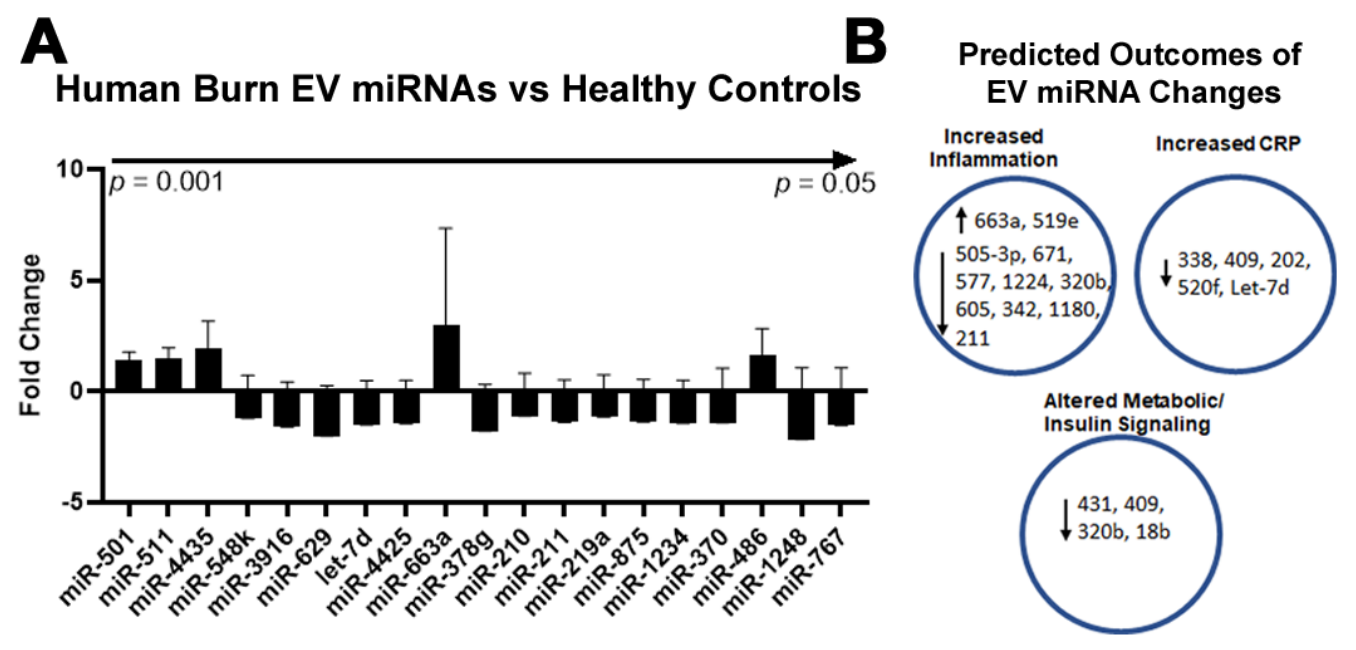

Figure 5. Proinflammatory miRNA signature in EVs from human burn patients by NanoString. Plasma EVs were isolated from human burn injury patients during the first $48 \mathrm{~h}$ of admission or healthy controls and miRNA content assessed by NanoString. (A) NanoString assessment of human burn patient EVs revealed that 26 miRNAs were significantly altered, 22 of which showed reduced expression. $n=3$ per group. (B) Predicted outcomes of changes in differentially expressed miRNAs. Directional changes in 11 of the miRNAs would promote inflammation, while reductions in 5 miRNAs that target CRP would promote CRP expression, and reductions in 4 miRNAs that target metabolic and insulin signaling could alter cellular metabolism.

\subsection{Plasma EV Number Correlates with Disease Severity}

Since we found a potential role for plasma EVs in modulating immune responses post-burn injury in the pre-clinical mouse model, and we found robust protein changes in APR proteins CRP and SAA1, we assessed plasma EV composition in a larger cohort of human burn patients from our human burn patient repository. EVs isolated early after burn injury from 50 burn patients were isolated. The clinical characteristics of these patients was similar to our mouse burn injury model with an average \%TBSA injury of $18.4 \%$ and plasma collected within the first $72 \mathrm{~h}$ after injury (Table 3 ). The majority of patients were male $(68 \%)$ consistent with historic trends in burn patient populations. 
Table 3. Clinical features of human burn injury patients. Key: TBSA-Total body surface area; LOS-Length of Stay; Mean \pm SEM.

\begin{tabular}{ccccc}
\hline \%TBSA Injury & Age & Sex \# (\%) & LOS & Mortality \# (\%) \\
\hline \multirow{2}{*}{$18.4 \pm 1.7$} & $50.3 \pm 2.2$ & $\mathrm{M}-34(68)$ & & Overall-4 (8) \\
& & $\mathrm{F}-16(32)$ & $49.4 \pm 5.7$ & $\mathrm{M}-2(5.8)$ \\
& & & $\mathrm{F}-2(12.5)$ \\
\hline
\end{tabular}

We first measured the number of EVs from each subject in plasma collected within $72 \mathrm{~h}$ of burn injury. This early time point was assessed in hopes of identifying mediators that might predict outcome in this patient population. The average concentration of EVs was $5.4 \times 10^{11} / \mathrm{mL}$ (Figure 6A). There was no difference in EV concentrations between males and females, and the majority of vesicles $(>70 \%)$ were within the MV size range of 100-500 nm. To confirm the presence of MVs, Western blot was performed on human EVs for MV marker Annexin-A1 (Figure 6B) [14]. Each of the subjects assessed was found to have Annexin-A1 in the isolated EVs, consistent with the presence of MVs in the preparation. The concentration of EVs was found to be positively correlated with the $\%$ TBSA burn injury $(\mathrm{r}=0.3, * p<0.05$, Figure $6 \mathrm{C})$. However, there was no association between plasma MV concentration and the length of stay (LOS) in the hospital, indicating EV number alone early after burn injury is not a strong predictor of hospital course. Therefore, we turned our attention to CRP and SAA1, which were found to be increased by LC-MS/MS in the smaller subset of patients above.

A

A Average Human Burn EV

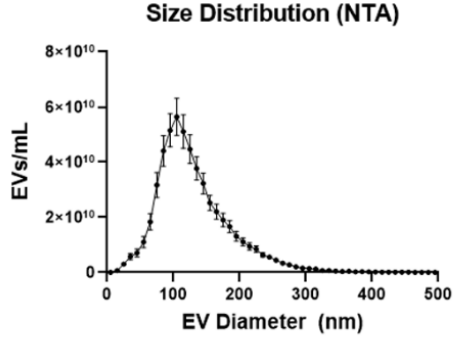

C

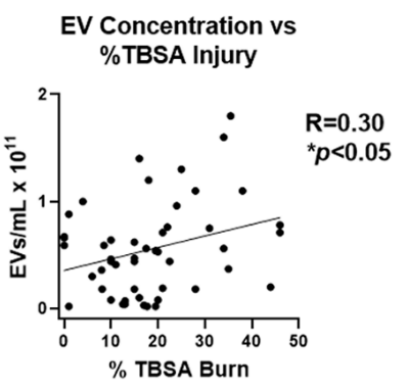

B

\section{Annexin A1 in Human Burn EVs}

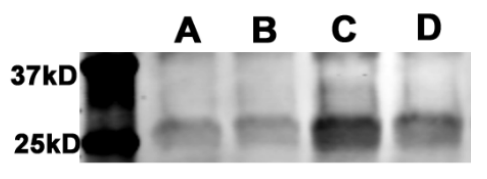

D

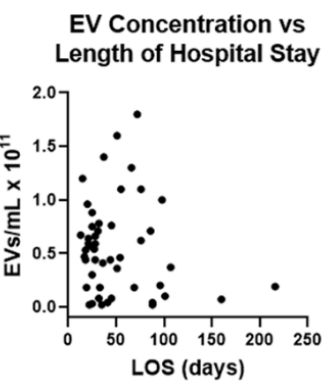

Figure 6. Assessment of human plasma EVs from human burn patients. Plasma EVs were isolated from 50 human burn patients within the first $72 \mathrm{~h}$ of admission. (A) Assessment of EV sign distribution by nanoparticle tracking analysis (NTA) found the majority of EVs were within the MV size range. (B) Western blot on EVs isolated from 4 human burn patients stained for MV marker Annexin-A1. (C) EV concentration was positively correlated with size of burn injury. (D) No correlation between EV concentration and length of hospital stay was found across subjects.

2.6. Human Burn Patients Have Increased Levels of CRP and SAA1 in Plasma EVs That Predict Hospital Length of Stay

Since both CRP and SAA1 were found to be increased in human burn EVs isolated during the first $72 \mathrm{~h}$ of injury (with SAA1 also being increased in mouse burn-EVs), we measured CRP and SAA1 by ELISA in EVs and the remaining plasma supernatant in our 
larger cohort to assess for their association with burn injury severity and LOS in the hospital. LOS is a key clinical endpoint that conveys the severity of the illness or disease. This would allow us to determine if these identified markers could serve as biomarkers to identify high-risk patients. As shown in Figure 6A, the majority of isolated EVs were in the MV size range (100-500 nm diameter). However, since some overlap occurs between exosomes and MVs near the $100 \mathrm{~nm}$ size range, we refer to the plasma supernatant as MV-depleted plasma (as apoptotic bodies and MVs are primarily removed by the $21,000 \times g$ spin, yet exosomes will remain) and the $21,000 \times g$ pellet as EVs since there may be both MVs and larger exosomes present. In the MV-depleted plasma, CRP levels were stable across all severities of burn injury (Figure 7A) and LOS (not shown); however, in the EV fraction, CRP levels were positively correlated with the severity of burn injury (Figure 7B). In males, the level of CRP in EVs isolated during the first $72 \mathrm{~h}$ of admission did not associate with hospital LOS (Figure 7C). However, in females, EV CRP levels were strongly associated with LOS $\left(r=0.56,{ }^{*} p<0.05\right.$, Figure 7D). A similar pattern was found with SAA1. There was no association of SAA1 in the MV-depleted plasma with burn severity (Figure 7E); however, EV SAA1 was positively correlated with the size of burn injury (Figure 7F). There was no correlation between EV SAA1 and LOS in males (Figure 7G); however in females, EV SAA1 was strongly correlated with LOS $\left(\mathrm{r}=0.58,{ }^{*} p<0.05\right.$, Figure $\left.7 \mathrm{H}\right)$. Both CRP and SAA1 levels were correlated with each other (Figure 7I), suggesting similar pathways may result in their secretion in vesicles. Together, these data implicate these two APR proteins that were identified by unbiased proteomic analysis as early indicators of burn injury severity that are associated with length of hospital stay in females.

A

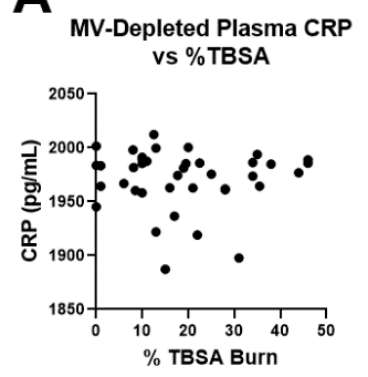

D

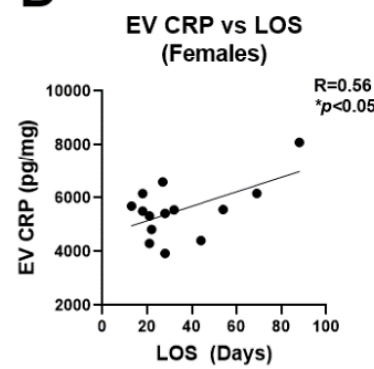

G

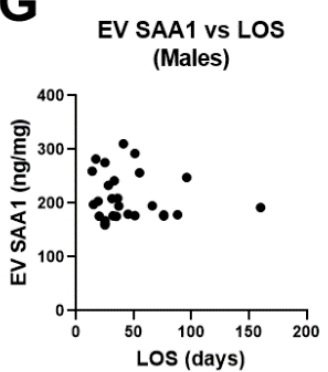

B

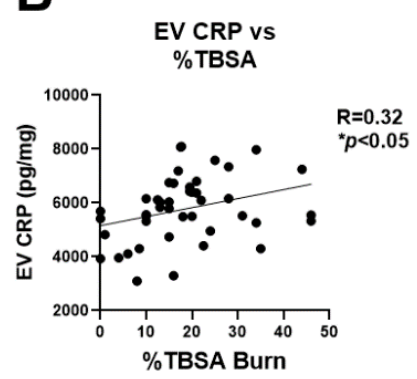

E MV-Depleted Plasma SAA1 vs $\%$ TBSA

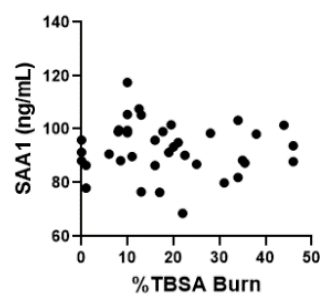

H

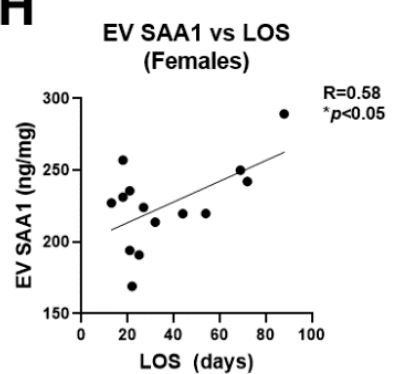

C

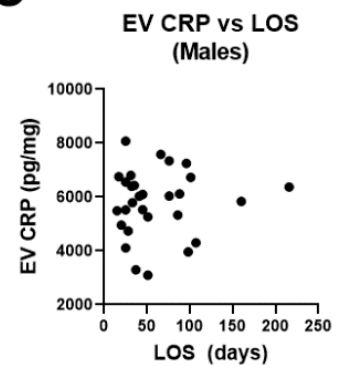

F

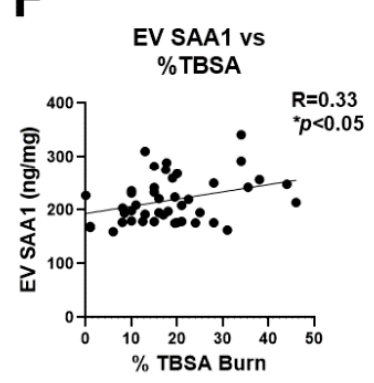

I

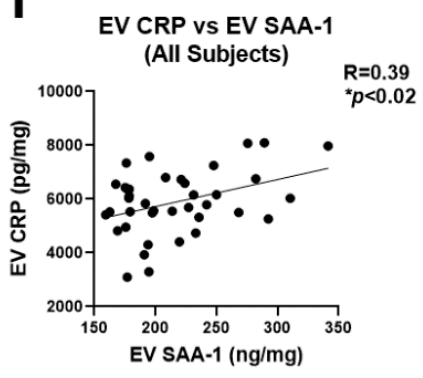

Figure 7. Association of EV CRP and SAA-1 in EVs with length of hospital stay in severe burn injury. EVs were isolated from 50 human burn patients and levels of CRP (A-D) and SAA1 (E-H) measured 
by ELISA and their association with length of stay (LOS) in the hospital were determined. (A) CRP levels from MV-depleted plasma showed no association with severity of burn injury. (B) CRP levels in EVs from human burn patients showed a positive correlation with severity of burn injury. $r=0.32$, ${ }^{*} p<0.05$. (C) CRP levels in EVs of male human burn patients was not related to LOS. (D) CRP concentration in EVs from female burn patients was positively correlated with hospital LOS $(\mathrm{r}=0.56$, ${ }^{*} p<0.05$ ). (E) SAA1 protein concentration in MV-depleted plasma showed no association with severity of burn injury. (F) SAA1 concentrations in EVs from human burn patients showed a positive correlation with severity of burn injury. $\mathrm{r}=0.33,{ }^{*} p<0.05$. (G) SAA1 concentrations in EVs of male human burn patients was not related to LOS. (H) SAA1 concentration in EVs from female burn patients was positively correlated with hospital LOS $\left(\mathrm{r}=0.58,{ }^{*} p<0.05\right)$. (I) Concentrations of CRP and SAA1 in EVs were significantly correlated with each other. $r=0.39, * p<0.02$.

\section{Discussion}

Burn injury is one of the most severe forms of trauma and often results in profound immune, metabolic, and cardiovascular dysregulation. Even long after the repair of skin barrier function by skin grafting, persistent physiological derangements persist. After resolution of the initial burn shock, mortality occurs weeks after injury, mostly due to infectious or cardiovascular complications [32-39]. The ability to identify high-risk individuals at the time of injury could greatly benefit care. Further, the identification of molecular mediators that could be targeted for intervention could lead to new therapeutic approaches. Currently, the standard of care for severe burn injuries is primarily supportive care and restoration of skin barrier function. This involves volume resuscitation during the early shock phase followed with critical ICU care providing respiratory and other organ support as needed. Once recovery from skin grafting or other surgical interventions is complete, normalization of physiology is the priority. Unfortunately, many patients experience secondary infections days to weeks after skin coverage is regained along with cardiopulmonary and other complications. Currently, there exist neither any early interventions that can prevent future morbidity nor any early diagnostic approaches to identify at-risk individuals.

In this study, we investigated if circulating EVs that are released early after burn injury promote immune dysfunction and could be used as biomarkers to identify atrisk patients. Prior work has found that EVs are increased after burn injuries in human patients and rodent models, and carry proinflammatory cytokines and TLR-activating DAMPs $[5,13]$. Here, we found that EVs secreted during the first $48 \mathrm{~h}$ after burn injury in mice are immunogenic, profoundly increasing proinflammatory cytokine secretion and proinflammatory signaling in splenic macrophages. TLR, cytokine, host-pathogen interaction, NFKB and innate immune system pathways were strongly increased by burn EVs. These findings are consistent with a recent report using RAW264.7 cells and bone marrow-derived macrophages [6]. These pathways are key for innate immune function and are known to play a role in burn-induced immune responses [40,41], suggesting EVs might play a role in driving immune responses early after burn injury. Importantly, we recently reported that post-burn EVs have similar effects in vivo as our findings here in vitro [6]. It is currently unclear if these responses might be protective, detrimental, or both. However, the majority of work suggests that early proinflammatory responses after burn injury may ultimately be counter-productive, resulting in long-term immune dysfunction after the resolution of the early burn shock [42,43]. Therefore, finding therapeutic targets that either reduce or modulate heightened early proinflammatory responses could be beneficial for patient care.

In order to identify new potential mediators in EVs that could be targeted therapeutically, we performed LC-MS/MS and NanoString ${ }^{\mathrm{TM}}$ analysis on burn EVs. We found some commonalities between the components in both human and mouse EVs, such as the APR protein SAA1 and increases in circulating complement/coagulation factors. These differences were found with sample size of 3 per group in each species. If the sample size were increased, it is possible that additional mediators would reach statistical significance, making this a limitation of this study. The finding of increased C5aR1 in human burn 
patients is consistent with a recent report finding increased $\mathrm{C} 5 \mathrm{aR} 1$ on granulocyte derived MVs in polytraumatized patients that could promote coagulation [44]. Further, we found CRP was increased in human burn patient EVs. CRP binds to phosphatidylcholine in membranes of apoptotic or necrotic cellular remains, or EVs potentially, and activates complement cascades to promote their uptake by phagocytic cells [45-47]. After burn injury, a significant amount of necrotic and apoptotic debris is released that may warrant this induction of CRP in EVs. SAA1 also promotes phagocytosis in macrophages and is a ligand for TLR4 [48-50], which is induced early after burn injury $[7,20]$. Both SAA1 and CRP correlated with \%TBSA burn injury across all subjects and length of hospital stay in females. It is currently unclear why there were differences between males and females. However, immune regulation between the two sexes is often divergent in the setting of injury [9]. Similar to our findings, CRP was recently reported to be increased in EVs of patients with sepsis and to promote proinflammatory responses in macrophages [51].

We found that neither CRP nor SAA1 in EV-depleted plasma was associated with severity of burn injury or length of hospital stay. This suggests that EVs may be a specific and active reservoir that can regulate post-traumatic pathology and be assessed for biomarkers. It is important to note that we used a centrifugation method to isolate EVs, which could readily be adopted in most hospital laboratories. It is difficult to definitively determine the type of $\mathrm{EV}$ present in any preparation, as size overlap between exosomes and MVs occurs in the size range of these preparations [14,15]. Additionally, it is possible that larger lipoprotein complexes could be included. However, our protocol mimics the most likely procedures that could be feasibly used by most hospital laboratories. Regardless of the exact subcellular vesicular localization, we identify relevant molecules that may serve as potential biomarkers or therapeutic targets.

Our findings, as well as other work, suggest that EVs are specific mediators of signaling after trauma that might be targeted therapeutically or used as predictors of hospital course. Our miRNA assessments and ex vivo EV transfers further suggest that early proinflammatory responses seen after burn injury are at least in part initiated by EVs. For instance, in human burn EVs, several miRNAs that are known to or are predicted to dampen inflammatory signaling were reduced, while some that promote proinflammatory signaling pathways were increased (see Figure 5 and Table S1). Further supporting a role for EVs as dynamic regulators of molecular signaling was the reduction in the presence of five miRNAs known to inhibit CRP expression, while CRP itself was increased in human burn EVs. Coupled with the functional studies in adoptive transfer to splenic macrophages, this work suggests that EVs are actively regulating immune and potentially other responses after severe trauma. We recently reported that EVs isolated from burn-injured mice and transferred to naïve, unburned mice recapitulate much of the immune response seen with burn injury itself [6]. Further, in their study finding increased EV CRP in sepsis patients, Fendl et al. found that depletion of CRP+ EVs from septic patients reduced the pro-inflammatory activity of septic plasma. This occurred even though the majority of CPR in plasma was not bound to EVs [51]. Therefore, this and other work implicates EVs as specific mediators of immune activation after trauma. Further work is needed to clearly define the temporal changes in EV contents and activity after injury. Additionally, studies assessing the effects of human post-burn EVs on human immune cell function are needed. In future studies we plan to do this using induced pluripotent stem cells (IPSCs) differentiated into human monocytes, neutrophils, epithelial cells, and endothelial cells.

Together, findings presented here as well as recent work by other groups indicate that EVs are key regulatory mediators in settings of trauma. Their contents may predict outcomes in specific patient populations such as males versus females. They also provide insight into cellular and organ dysfunction throughout the body and may be used to identify novel therapeutic targets or approaches. Future work will study the utility of EV replacement therapy or dialysis in improving outcomes in the setting of severe burn injury. 


\section{Materials and Methods \\ 4.1. Mouse $20 \%$ TBSA Thermal Injury}

All procedures were conducted in strict adherence to the Guide for the Care and Use of Laboratory Animals of the National Institute of Health and approved by the University of North Carolina Institutional Animal Care and Use Committee under protocol \#21-082. Mice were housed in American Association for Accreditation of Laboratory Animal Care (AAALAC)-accredited facilities with $24 \mathrm{~h}$ veterinary care and close observation throughout the experiment. Measures were taken to alleviate suffering, with all injuries performed under avertin anesthesia with appropriate analgesia. Mice underwent a 20\% total body surface area (TBSA) thermal injury to model a large burn injury in humans as described previously $[5,6,22,23]$. Briefly, C57BL6 mice (female, $6-8$ weeks old, 15-20 g) first were anesthetized with tribromoethanol/avertin $(475 \mathrm{mg} / \mathrm{kg}$; Sigma-Aldrich, Burlington MA, USA). Their targeted region on the dorsum was then shaved (NC0854145; Fisher, Pittsburg, PA, USA) prior to injection of subcutaneous morphine sulfate $(3 \mathrm{mg} / \mathrm{kg}$; Westward, Berkeley Heights, NJ, USA). Four defined skin locations were then contacted for $10 \mathrm{~s}$ with a copper rod heated to $100{ }^{\circ} \mathrm{C}$ in a water bath. Mice were then resuscitated with Ringer's lactate $(0.1 \mathrm{~mL} / \mathrm{g}$ body weight). Post-procedure analgesia was maintained with morphine sulfate-supplemented water $(60 \mu \mathrm{g} / 20 \mathrm{~g}$ mouse) ad lib for the duration of the experiment. Sham mice underwent identical treatment minus application of a heated copper rod. Mice were monitored at least twice daily for the duration of the experiment. Mice that showed signs of distress including a $>15 \%$ loss of body weight, difficulty breathing, hunching over, dehydration, inactivity, or growing lesions were humanely euthanized immediately. There was zero burn-related mortality.

\subsection{EV Isolation, Quantification, and Sizing}

EVs were isolated from plasma of human burn patients collected $0-72 \mathrm{~h}$ after injury or mice at 24 and $72 \mathrm{~h}$ after injury using sequential centrifugation as we have described previously. This process results in isolation of EVs primarily between $100 \mathrm{~nm}$ and $1 \mu \mathrm{m}$ in diameter (primarily the MV size range), which we have confirmed by flow cytometry and nanoparticle tracking analysis (NTA) $[5,29,30]$. Briefly, anticoagulated plasma was centrifuged at $2000 \times g$ for $20 \mathrm{~min}$ to remove cells, followed by a $10,000 \times g$ spin of the supernatant for $30 \mathrm{~min}$ to remove cellular debris, and a final $21,000 \times g$ spin of remaining supernatant for $1 \mathrm{~h}$ to pellet the EVs. EV concentration $(\mathrm{EVs} / \mathrm{mL})$ and size distributions were measured by NTA using the ZetaView QUATT Particle Metrix machine at a 1:1000 dilution in ultrafiltered PBS.

\subsection{Splenic Macrophage Culture and EV-Stimulation}

Total splenocytes, which were obtained from spleen female C57BL/6 mice, underwent red-cell lysis by Ammonium-Chloride-Potassium (ACK) buffer exposure, were suspended into RPMI1640 media supplemented with 10\% fetal bovine serum, $1 \%$ penicillin/streptomycin, and $100 \mathrm{ng} / \mathrm{mL}$ rhM-CSF at a density of $3 \times 10^{5}$ cells $/ \mathrm{mL}$ in $75 \mathrm{~mL}$ tissue culture plates, and cultured at $37^{\circ} \mathrm{C}$ and $5 \% \mathrm{CO}_{2}$ for 7 days. Non-adherent cells were removed every other day. Resultant adherent splenic macrophages were harvested from plates by dispase treatment, and $1 \times 10^{6}$ were replated into 24 well plates and rested for $24 \mathrm{~h}$. Cells were then exposed to $3 \times 10^{7} \mathrm{EV}$ s from burn- or sham-injured mice for $24 \mathrm{~h}$. Supernatants and cells were harvested for analyses.

EV adoptive transfer to splenic macrophage cultures: EVs were collected from plasma of six mice $24 \mathrm{~h}$ after burn injury (burn-EVs) or sham exposure (sham-EVs). $1 \times 10^{10} \mathrm{EVs}$ in sterile PBS were adoptively transferred to $1 \times 10^{6}$ splenic macrophages, which was $\sim 15 \%$ of total media EVs of naïve splenic macrophage cultures. Treated cells were harvested $24 \mathrm{~h}$ after exposure for cytokine and chemokine measurement. 


\subsection{Measurement of Cytokines and Chemokines in Burn-and Sham-EV Treated Splenic Macrophages}

Macrophage media and cell lysates were collected, and the Bio-Plex Multi-Plex Immunoassays (BioRad) used to measure IL-1 $\beta$, IL-2, IL-6, IL-8, IL-10, IL-12(p70), IFN-g, MCP-1, and TNF $\alpha$, according to the manufacturer's instructions. The Bio-plex $200^{\circledR}$ system with Bio-Plex Manager and Bio-Plex Data Pro Software was used to capture and analyze data. A 5-paramater logistic spline-curve fitting method was used to calculate final values which were measured in $\mathrm{pg} / \mathrm{mL}$.

\subsection{Macrophage Immune Gene Detection and Quantification by NanoString}

Isolation of mRNA was performed as previously described [5]. Briefly, macrophages were lysed with TRIZOL buffer (Sigma) and total RNA was isolated by chloroform extraction and quantified $\left(\mathrm{A}_{260} / \mathrm{A}_{280}\right.$ and $\left.\mathrm{A}_{260} / \mathrm{A}_{230}\right)$ using a nanodrop $2000 \mathrm{TM}$ spectrophotometer (NanoDrop Technologies, Waltham, MA, USA). NanoString technology and the nCounter Mouse Immunology Panel (Nanostring Technologies, Seattle, WA, USA) was used to simultaneously evaluate $561 \mathrm{mRNAs}$ in each sample [52]. Each sample was run in triplicate. Briefly, a total of $100 \mathrm{ng}$ mRNA was hybridized to report-capture probe pairs (CodeSets) at $65{ }^{\circ} \mathrm{C}$ for $18 \mathrm{~h}$. After this solution-phase hybridization, the nCounter Prep Station was used to remove excess probe, align the probe/target complexes, and immobilize these complexes in the nCounter cartridge. The nCounter cartridge was then placed in a digital analyzer for image acquisition and data processing. The expression level of each gene was measured by counting the number of times the color-coded barcode for that gene was detected, and the barcode counts tabulated. nSolver v4.0, an integrated analysis platform was used to generate appropriate data normalization as well as fold-changes, resulting ratios, and differential expression. nCounter ${ }^{\mathrm{TM}} \mathrm{v} 4.0$ Advanced Analysis and $\mathrm{R}$ statistics were used to identify pathway-specific responses [52].

\subsection{Recruitment of Human Burn Patients and Collection of Human Plasma and Multiplexed NanoString Measurement of miRNAs in Human EVs}

Blood samples from burn patients admitted to the North Carolina Jaycee Burn Center and recruited into an IRB-approved repository protocol (IRB 04-1437) were collected and stored. Patients received standard of care and care was not affected by study participation. Patients were not excluded from the study based on burn size, inhalation injury, or factors including age, race, or substance use prior to injury. Patients were followed until discharge or expiration. This study utilized plasma samples collected early after injury (1-3 days) from 50 recruited patients.

EV were purified from plasma of burn patients and healthy donors. In order to interrogate the miRNA cargo of these EVs, we employed NanoString technology and the nCounter Human miRNA Panel v2 allowing for simultaneous evaluation of $800 \mathrm{miR}$ NAs [21]. RNA was isolated from EVs which were disrupted with $10 \%$ TritonX. The exoRNeasy Kit Part II (QIAcube), and miRNA easy Kit were used for total mRNA isolation as per the manufacturer's protocol; the quantity and quality of the mRNA in each sample was determined $\left(\mathrm{A}_{260} / \mathrm{A}_{280}\right.$ and $\left.\mathrm{A}_{260} / \mathrm{A}_{230}\right)$ by a NanoDrop (ND1000). $100 \mathrm{ng}$ of total EV mRNA was used for human NanoString nCounter miRNA microarray assay according to the manufacturer's instructions. miRNAs were hybridized to probes at $65^{\circ} \mathrm{C}$ for $30 \mathrm{~h}$. Hybridized probes were extended and quantified using the nCounter Prep Station and Digital Analyzer. The nCounter-generated relative fluorescent intensities were analyzed using nSolver 4.0 software according to the manufacturer's instructions.

\subsection{Unbiased Proteomic Assessment of EVs from Mice and Humans and Using LC-MS/MS}

EVs were isolated from sham-injured mice, 20\% TBSA burn injury mice, healthy humans, and human burn patients. Plasma from mice was collected $72 \mathrm{~h}$ after injury, and plasma from human burn patients within the first $72 \mathrm{~h}$ of injury/hospital admission. After the final spin, EVs were resuspended in $20 \mathrm{mM}$ Tris buffer (pH 7.5). The UNC Proteomics Core LFQ strategy was applied as described previously [53-55]. Sample Preparation for 
Proteomics Analysis: $8 \mathrm{M}$ urea was added to the in-solution protein samples ( 10-20 $\mu \mathrm{g}$ per replicate, $n=3$ ), then reduced with $5 \mathrm{mM}$ DTT for $30 \mathrm{~min}$ and alkylated with $15 \mathrm{mM}$ iodoacetamide for $45 \mathrm{~min}$. The samples were diluted to $1 \mathrm{M}$ urea, then digested with MS grade trypsin (Promega) at $37^{\circ} \mathrm{C}$ overnight. The peptide samples were acidified to $1 \%$ TFA, then desalted using StrataX SPE cartridges (Phenomenex). The samples were dried via vacuum centrifugation, then resuspended in $0.1 \%$ formic acid for BCA colorimetric peptide quantitation assay (Pierce). LC-MS/MS Analysis: Samples were normalized, and $0.5 \mu \mathrm{g}$ of each sample was analyzed by LC-MS/MS using an Easy nLC 1200 coupled to a QExactive HF (Thermo Scientific, Waltham, MA, USA). Samples were injected onto an Easy Spray PepMap C18 column $(75 \mu \mathrm{m}$ id $\times 25 \mathrm{~cm}, 2 \mu \mathrm{m}$ particle size) (Thermo Scientific, Waltham, MA, USA) and separated over a 90 min period. The gradient for separation consisted of $5-32 \%$ mobile phase $\mathrm{B}$ at a $250 \mathrm{~nL} / \mathrm{min}$ flow rate, where mobile phase A was $0.1 \%$ formic acid in water and mobile phase B consisted of $0.1 \%$ formic acid in ACN. The QExactive HF was operated in data-dependent mode where the 15 most intense precursors were selected for subsequent HCD fragmentation. Resolution for the precursor scan $(\mathrm{m} / \mathrm{z}$ $350-1700$ ) was set to 60,000 with a target value of $3 \times 106$ ions, $100 \mathrm{~ms}$ inject time. MS/MS scans resolution was set to 15,000 with a target value of $1 \times 105$ ions, $75 \mathrm{~ms}$ inject time. The normalized collision energy was set to $27 \%$ for HCD, with an isolation window of $1.6 \mathrm{~m} / \mathrm{z}$. Peptide match was set to preferred, and precursors with unknown charge or a charge state of 1 and $\geq 7$ were excluded. The concentration of SAA1 protein was verified by ELISA by following the manufacturer's instructions ( $\mathrm{R}$ and D systems, DY2948).

\subsection{Statistical Analyses}

LC-MS/MS. The UNC Proteomics Core Facility is well versed in quantitative proteomics strategies to identify regulators [53-56]. Raw data files were processed using MaxQuant version 1.6.3.4 and searched against the reviewed human database (containing 20,245 sequences) or the reviewed mouse database (containing 16,940 sequences) Andromeda within MaxQuant [57]. Enzyme specificity was set to trypsin, up to two missed cleavage sites were allowed, carbamidomethylation of Cys was set as a fixed modification and oxidation of Met was set as a variable modification. Label-free quantification (LFQ) using razor + unique peptides was enabled. A $1 \%$ false discovery rate (FDR) was used to filter all data. Additional analysis was performed in Perseus GraphPad and DAVID bioinformatics. A minimum of 2 unique peptides per protein and $>50 \%$ non-zero values across the datasets were required for quantification. Imputation of missing values based on normal distribution with width of 0.3 and downshift of 1.8, was performed. A LFQ $\log 2$ fold change ratio for each pairwise comparison was calculated. Student's $t$-test was performed for each pairwise comparison (mouse burn_control; human burn_control) and a $p$-value $<0.05$ was considered statistically significant. Nanostring: The proprietary analysis software for NanoString, nSolver v4.0, was used to appropriately normalize miRNA or mRNA levels and fold-changes, giving ratios and differential expression. For pathway analysis, nCounter ${ }^{\mathrm{TM}} \mathrm{v} 4.0$ Advanced Analysis and Ingenuity Pathway Analysis package with robust $R$ statistics were used to determine pathway-specific changes [52].

\section{Conclusions}

Plasma EVs released early after large burn injury enhance immune dysfunction after injury and could be used as a form of liquid biopsy to identify high-risk patients. EVs isolated within 3 days after injury from human burn patients were found to be enriched with SAA1 and CRP, which correlated with length of hospital stay in female patients. Future studies will investigate if removal of pro-inflammatory EVs improves outcomes in pre-clinical models of burn injury.

Supplementary Materials: The following are available online at https://www.mdpi.com/article/10 .3390/ijms221810083/s1. 
Author Contributions: Conceptualization, L.G.C.J., R.M. and S.W.; methodology, R.M., S.W., M.L.W., L.E.H., A.P., C.M. and L.G.C.J.; software, R.M.; validation, R.M., S.W., M.L.W., L.E.H., A.P., C.M. and L.G.C.J.; formal analysis, R.M., M.L.W., L.E.H., A.P. and L.G.C.J.; investigation, R.M., S.W. and L.G.C.J.; resources, R.M., S.W., B.C. and L.G.C.J.; data curation, R.M., M.L.W., L.E.H., A.P., C.M. and L.G.C.J.; writing-original draft preparation, R.M., M.L.W., L.E.H. and L.G.C.J.; writing-review and editing, R.M., S.W., M.L.W., L.E.H. and L.G.C.J.; visualization, R.M. and L.G.C.J.; supervision, R.M., S.W., B.C. and L.G.C.J.; project administration, R.M., S.W., and L.G.C.J.; funding acquisition, R.M., B.C. and L.G.C.J. All authors have read and agreed to the published version of the manuscript.

Funding: This research was funded by NIH, grant numbers: GM131124, GM008450, ES007126, AA024829, AA028924, AA028599 and The Jaycee Burn Trust.

Institutional Review Board Statement: The study was conducted according to the guidelines of the Declaration of Helsinki, and approved by the University of North Carolina Institutional Animal Care and Use Committee (protocol code \#21-082 approved 31 March 2021) for animal experiments and the Institutional Review Board (protocol code 04-1437 approved 9 August 2020).

Informed Consent Statement: Informed consent was obtained from all subjects involved in the study.

Data Availability Statement: The mass spectrometry proteomics data have been deposited to the ProteomeXchange Consortium via the PRIDE partner repository with the dataset identifier PXD028515. NanoString miRNA data has been uploaded into GEO. Other primary data can be made available from the authors upon reasonable request.

Acknowledgments: We acknowledge the UNC Delta Translational Recharge Center for their support. This research is based in part upon work conducted using the UNC Proteomics Core Facility, which is supported in part by P30 CA016086 Cancer Center Core Support Grant to the UNC Lineberger Comprehensive Cancer Center. We thank the Jaycee Burn Center patients and families for their contribution. We thank Jennie Vaughn for her grammatical editing.

Conflicts of Interest: The authors declare no conflict of interest. The funders had no role in the design of the study; in the collection, analysis, or interpretation of data; in the writing of the manuscript, or in the decision to publish the results.

\section{References}

1. Peck, M.; Molnar, J.; Swart, D. A global plan for burn prevention and care. Bull. World Health Organ. 2009, 87, 802-803. [CrossRef]

2. Miller, S.F.; Bessey, P.; Lentz, C.W.; Jeng, J.C.; Schurr, M.; Browning, S.; Committee, A.N. National burn repository 2007 report: A synopsis of the 2007 call for data. J. Burn Care Res. 2008, 29, 862-870; discussion 871. [CrossRef]

3. ABA National Burn Repository. Burn Incidence and Treatment in the United States: 2016. Available online: http://ameriburn. org/resources_factsheet.php (accessed on 1 September 2021).

4. Maile, R.; Jones, S.; Pan, Y.; Zhou, H.; Jaspers, I.; Peden, D.B.; Cairns, B.A.; Noah, T.L. Association between early airway damage-associated molecular patterns and subsequent bacterial infection in patients with inhalational and burn injury. Am. J. Physiol. Lung Cell. Mol. Physiol. 2015, 308, L855-L860. [CrossRef]

5. Coleman, L.G., Jr.; Maile, R.; Jones, S.W.; Cairns, B.A.; Crews, F.T. HMGB1/IL-1beta complexes in plasma microvesicles modulate immune responses to burn injury. PLoS ONE 2018, 13, e0195335. [CrossRef] [PubMed]

6. Willis, M.L.; Mahung, C.; Wallet, S.M.; Barnett, A.; Cairns, B.A.; Coleman, L.G., Jr.; Maile, R. Plasma extracellular vesicles released after severe burn injury modulate macrophage phenotype and function. J. Leukoc. Biol. 2021, 1, 17.

7. Cairns, B.A.; Barnes, C.M.; Mlot, S.; Meyer, A.A.; Maile, R. Toll-like receptor 2 and 4 ligation results in complex altered cytokine profiles early and late after burn injury. J. Trauma Acute Care Surg. 2008, 64, 1069-1078. [CrossRef]

8. Moore, C.B.; Medina, M.A.; van Deventer, H.W.; O'Connor, B.P.; Cameron, S.; Taxman, D.J.; Maile, R.; Ting, J.P.; Cairns, B.A. Downregulation of immune signaling genes in patients with large surface burn injury. J. Burn Care Res. 2007, 28, 879-887. [CrossRef] [PubMed]

9. Bird, M.D.; Karavitis, J.; Kovacs, E.J. Sex differences and estrogen modulation of the cellular immune response after injury. Cell. Immunol. 2008, 252, 57-67. [CrossRef] [PubMed]

10. van Niel, G.; D'Angelo, G.; Raposo, G. Shedding light on the cell biology of extracellular vesicles. Nat. Rev. Mol. Cell Biol. 2018, 19, 213-228. [CrossRef] [PubMed]

11. Raeven, P.; Zipperle, J.; Drechsler, S. Extracellular Vesicles as Markers and Mediators in Sepsis. Theranostics 2018, 8, 3348-3365. [CrossRef]

12. Tricarico, C.; Clancy, J.; D'Souza-Schorey, C. Biology and biogenesis of shed microvesicles. Small GTPases 2017, 8, 220-232. [CrossRef] [PubMed]

13. O'Dea, K.P.; Porter, J.R.; Tirlapur, N.; Katbeh, U.; Singh, S.; Handy, J.M.; Takata, M. Circulating Microvesicles Are Elevated Acutely following Major Burns Injury and Associated with Clinical Severity. PLoS ONE 2016, 11, e0167801. [CrossRef] [PubMed] 
14. Jeppesen, D.K.; Fenix, A.M.; Franklin, J.L.; Higginbotham, J.N.; Zhang, Q.; Zimmerman, L.J.; Liebler, D.C.; Ping, J.; Liu, Q.; Evans, R.; et al. Reassessment of Exosome Composition. Cell 2019, 177, 428-445.e18. [CrossRef] [PubMed]

15. Mathieu, M.; Martin-Jaular, L.; Lavieu, G.; Thery, C. Specificities of secretion and uptake of exosomes and other extracellular vesicles for cell-to-cell communication. Nat. Cell Biol. 2019, 21, 9-17. [CrossRef]

16. Yang, H.; Ochani, M.; Li, J.; Qiang, X.; Tanovic, M.; Harris, H.E.; Susarla, S.M.; Ulloa, L.; Wang, H.; DiRaimo, R.; et al. Reversing established sepsis with antagonists of endogenous high-mobility group box 1. Proc. Natl. Acad. Sci. USA 2004, 101, $296-301$. [CrossRef]

17. Liu, L.; Fahy, K.E.; Awoyemi, A.A.; Thapa, P.; Kelly, L.E.; Chen, J.; Bihl, J.C.; Cool, D.R.; Chen, Y.; Rapp, C.M.; et al. Thermal Burn Injury Generates Bioactive Microvesicles: Evidence for a Novel Transport Mechanism for the Lipid Mediator Platelet-Activating Factor (PAF) That Involves Subcellular Particles and the PAF Receptor. J. Immunol. 2020, 205, 193-201. [CrossRef]

18. Eitas, T.K.; Stepp, W.H.; Sjeklocha, L.; Long, C.V.; Riley, C.; Callahan, J.; Sanchez, Y.; Gough, P.; Knowlin, L.; van Duin, D.; et al. Differential regulation of innate immune cytokine production through pharmacological activation of Nuclear Factor-Erythroid-2Related Factor 2 (NRF2) in burn patient immune cells and monocytes. PLoS ONE 2017, 12, e0184164. [CrossRef]

19. Kartchner, L.B.; Gode, C.J.; Dunn, J.L.M.; Glenn, L.I.; Duncan, D.N.; Wolfgang, M.C.; Cairns, B.A.; Maile, R. One-hit wonder: Late after burn injury, granulocytes can clear one bacterial infection but cannot control a subsequent infection. Burns 2019, 45, 627-640. [CrossRef] [PubMed]

20. Cairns, B.; Maile, R.; Barnes, C.M.; Frelinger, J.A.; Meyer, A.A. Increased Toll-like receptor 4 expression on T cells may be a mechanism for enhanced T cell response late after burn injury. J. Trauma Acute Care Surg. 2006, 61, 293-298; discussion 298-299. [CrossRef]

21. Dunn, J.L.; Hunter, R.A.; Gast, K.; Maile, R.; Cairns, B.A.; Schoenfisch, M.H. Direct detection of blood nitric oxide reveals a burn-dependent decrease of nitric oxide in response to Pseudomonas aeruginosa infection. Burns 2016, 42, 1522-1527. [CrossRef]

22. Dunn, J.L.M.; Kartchner, L.B.; Gast, K.; Sessions, M.; Hunter, R.A.; Thurlow, L.; Richardson, A.; Schoenfisch, M.; Cairns, B.A.; Maile, R. Mammalian target of rapamycin regulates a hyperresponsive state in pulmonary neutrophils late after burn injury. $J$. Leukoc. Biol. 2018, 103, 909-918. [CrossRef]

23. Dunn, J.L.M.; Kartchner, L.B.; Stepp, W.H.; Glenn, L.I.; Malfitano, M.M.; Jones, S.W.; Doerschuk, C.M.; Maile, R.; Cairns, B.A. Blocking CXCL1-dependent neutrophil recruitment prevents immune damage and reduces pulmonary bacterial infection after inhalation injury. Am. J. Physiol. Lung Cell. Mol. Physiol. 2018, 314, L822-L834. [CrossRef] [PubMed]

24. Jones, S.W.; Zhou, H.; Ortiz-Pujols, S.M.; Maile, R.; Herbst, M.; Joyner, B.L., Jr.; Zhang, H.; Kesic, M.; Jaspers, I.; Short, K.A.; et al. Bronchoscopy-derived correlates of lung injury following inhalational injuries: A prospective observational study. PLoS ONE 2013, 8, e64250. [CrossRef] [PubMed]

25. Neely, C.J.; Kartchner, L.B.; Mendoza, A.E.; Linz, B.M.; Frelinger, J.A.; Wolfgang, M.C.; Maile, R.; Cairns, B.A. Flagellin treatment prevents increased susceptibility to systemic bacterial infection after injury by inhibiting anti-inflammatory IL-10+ IL-12- neutrophil polarization. PLoS ONE 2014, 9, e85623.

26. van Duin, D.; Strassle, P.D.; DiBiase, L.M.; Lachiewicz, A.M.; Rutala, W.A.; Eitas, T.; Maile, R.; Kanamori, H.; Weber, D.J.; Cairns, B.A.; et al. Timeline of health care-associated infections and pathogens after burn injuries. Am. J. Infect. Control 2016, 44, 1511-1516. [CrossRef]

27. Durbin, E.A.; Gregory, M.S.; Messingham, K.A.; Fontanilla, C.V.; Duffner, L.A.; Kovacs, E.J. The role of interleukin 6 in interferongamma production in thermally injured mice. Cytokine 2000, 12, 1669-1675. [CrossRef] [PubMed]

28. Segura-Lepe, M.P.; Keun, H.C.; Ebbels, T.M.D. Predictive modelling using pathway scores: Robustness and significance of pathway collections. BMC Bioinform. 2019, 20, 543. [CrossRef]

29. Coleman, L.G., Jr.; Zou, J.; Crews, F.T. Microglial-derived miRNA let-7 and HMGB1 contribute to ethanol-induced neurotoxicity via TLR7. J. Neuroinflammation 2017, 14, 22. [CrossRef] [PubMed]

30. Crews, F.; Zou, J.; Coleman, L.G., Jr. Extracellular microvesicles promote microglia-mediated proinflammatory responses to ethanol. J. Neurosci. Res. 2021, 99, 1940-1956. [CrossRef] [PubMed]

31. Hou, J.; Li, X.; Xie, K.P. Coupled liquid biopsy and bioinformatics for pancreatic cancer early detection and precision prognostication. Mol. Cancer 2021, 20, 34. [CrossRef]

32. Brusselaers, N.; Logie, D.; Vogelaers, D.; Monstrey, S.; Blot, S. Burns, inhalation injury and ventilator-associated pneumonia: Value of routine surveillance cultures. Burns 2012, 38, 364-370. [CrossRef]

33. Chen, M.C.; Chen, M.H.; Wen, B.S.; Lee, M.H.; Ma, H. The impact of inhalation injury in patients with small and moderate burns. Burns 2014, 40, 1481-1486. [CrossRef]

34. Cioffi, W.G. What's new in burns and metabolism. J. Am. Coll. Surg. 2001, 192, 241-254. [CrossRef]

35. Jeschke, M.G.; Gauglitz, G.G.; Kulp, G.A.; Finnerty, C.C.; Williams, F.N.; Kraft, R.; Suman, O.E.; Mlcak, R.P.; Herndon, D.N. Long-term persistance of the pathophysiologic response to severe burn injury. PLoS ONE 2011, 6, e21245. [CrossRef] [PubMed]

36. Pruitt, B.A., Jr.; Wolf, S.E. An historical perspective on advances in burn care over the past 100 years. Clin. Plast. Surg. 2009, 36, 527-545. [CrossRef] [PubMed]

37. Strassle, P.D.; Williams, F.N.; Napravnik, S.; van Duin, D.; Weber, D.J.; Charles, A.; Cairns, B.A.; Jones, S.W. Improved Survival of Patients With Extensive Burns: Trends in Patient Characteristics and Mortality Among Burn Patients in a Tertiary Care Burn Facility, 2004-2013. J. Burn Care Res. 2017, 38, 187-193. [CrossRef] [PubMed] 
38. Thombs, B.D.; Singh, V.A.; Halonen, J.; Diallo, A.; Milner, S.M. The effects of preexisting medical comorbidities on mortality and length of hospital stay in acute burn injury: Evidence from a national sample of 31,338 adult patients. Ann. Surg. 2007, 245, 629-634. [CrossRef]

39. Veeravagu, A.; Yoon, B.C.; Jiang, B.; Carvalho, C.M.; Rincon, F.; Maltenfort, M.; Jallo, J.; Ratliff, J.K. National trends in burn and inhalation injury in burn patients: Results of analysis of the nationwide inpatient sample database. J. Burn Care Res. 2015, 36, 258-265. [CrossRef] [PubMed]

40. Chen, X.L.; Sun, L.; Guo, F.; Wang, F.; Liu, S.; Liang, X.; Wang, R.S.; Wang, Y.J.; Sun, Y.X. High-mobility group box-1 induces proinflammatory cytokines production of Kupffer cells through TLRs-dependent signaling pathway after burn injury. PLoS ONE 2012, 7, e50668. [CrossRef] [PubMed]

41. Lopez, N.E.; Krzyzaniak, M.; Costantini, T.W.; De Maio, A.; Baird, A.; Eliceiri, B.P.; Coimbra, R. Vagal nerve stimulation blocks peritoneal macrophage inflammatory responsiveness after severe burn injury. Shock 2012, 38, 294-300. [CrossRef] [PubMed]

42. Finnerty, C.C.; Jeschke, M.G.; Herndon, D.N.; Gamelli, R.; Gibran, N.; Klein, M.; Silver, G.; Arnoldo, B.; Remick, D.; Tompkins, R.G.; et al. Temporal cytokine profiles in severely burned patients: A comparison of adults and children. Mol. Med. 2008, 14, 553-560. [CrossRef]

43. Gauglitz, G.G.; Song, J.; Herndon, D.N.; Finnerty, C.C.; Boehning, D.; Barral, J.M.; Jeschke, M.G. Characterization of the inflammatory response during acute and post-acute phases after severe burn. Shock 2008, 30, 503-507. [CrossRef] [PubMed]

44. Karasu, E.; Demmelmaier, J.; Kellermann, S.; Holzmann, K.; Kohl, J.; Schmidt, C.Q.; Kalbitz, M.; Gebhard, F.; Huber-Lang, M.S.; Halbgebauer, R. Complement C5a Induces Pro-inflammatory Microvesicle Shedding in Severely Injured Patients. Front. Immunol. 2020, 11, 1789. [CrossRef] [PubMed]

45. Volanakis, J.E. Complement activation by C-reactive protein complexes. Ann. N. Y. Acad. Sci. 1982, 389, 235-250. [CrossRef]

46. Thompson, D.; Pepys, M.B.; Wood, S.P. The physiological structure of human C-reactive protein and its complex with phosphocholine. Structure 1999, 7, 169-177. [CrossRef]

47. Marnell, L.; Mold, C.; Du Clos, T.W. C-reactive protein: Ligands, receptors and role in inflammation. Clin. Immunol. 2005, 117, 104-111. [CrossRef] [PubMed]

48. Leow, K.Y.; Goh, W.W.; Heng, C.K. Effect of serum amyloid A1 treatment on global gene expression in THP-1-derived macrophages. Inflamm. Res. 2012, 61, 391-398. [CrossRef] [PubMed]

49. Farre-Alins, V.; Palomino-Antolin, A.; Narros-Fernandez, P.; Lopez-Rodriguez, A.B.; Decouty-Perez, C.; Munoz-Montero, A.; Zamorano-Fernandez, J.; Mansilla-Fernandez, B.; Giner-Garcia, J.; Garcia-Feijoo, P.; et al. Serum Amyloid A1/Toll-Like Receptor-4 Axis, an Important Link between Inflammation and Outcome of TBI Patients. Biomedicines 2021, 9, 599. [CrossRef] [PubMed]

50. Han, S.; Oh, J.H.; Shin, C.Y.; Yoon, H.S.; Lee, D.H.; Chung, J.H. Serum amyloid A1 is induced by UV irradiation and detected by toll-like receptor 4 to causes skin inflammation. J. Dermatol. Sci. 2016, 84, 107-110. [CrossRef]

51. Fendl, B.; Weiss, R.; Eichhorn, T.; Linsberger, I.; Afonyushkin, T.; Puhm, F.; Binder, C.J.; Fischer, M.B.; Weber, V. Extracellular vesicles are associated with C-reactive protein in sepsis. Sci Rep. 2021, 11, 6996. [CrossRef]

52. Kulkarni, M.M. Digital multiplexed gene expression analysis using the NanoString nCounter system. Curr. Protoc. Mol. Biol. 2011, 94, 25B.10.1-25B.10.17. [CrossRef]

53. O'Banion, C.P.; Priestman, M.A.; Hughes, R.M.; Herring, L.E.; Capuzzi, S.J.; Lawrence, D.S. Design and Profiling of a Subcellular Targeted Optogenetic cAMP-Dependent Protein Kinase. Cell Chem. Biol. 2018, 25, 100-109.e8. [CrossRef]

54. Kennedy, L.; Kaltenbrun, E.; Greco, T.M.; Temple, B.; Herring, L.E.; Cristea, I.M.; Conlon, F.L. Formation of a TBX20-CASZ1 protein complex is protective against dilated cardiomyopathy and critical for cardiac homeostasis. PLoS Genet. 2017, 13, e1007011. [CrossRef] [PubMed]

55. Ghosh, A.; Coakley, R.C.; Mascenik, T.; Rowell, T.R.; Davis, E.S.; Rogers, K.; Webster, M.J.; Dang, H.; Herring, L.E.; Sassano, M.F.; et al. Chronic E-cigarette Exposure Alters the Human Bronchial Epithelial Proteome. Am. J. Respir. Crit. Care Med. 2018, 198, 67-76. [CrossRef]

56. Yi, J.J.; Paranjape, S.R.; Walker, M.P.; Choudhury, R.; Wolter, J.M.; Fragola, G.; Emanuele, M.J.; Major, M.B.; Zylka, M.J. The autism-linked UBE3A T485A mutant E3 ubiquitin ligase activates the Wnt/beta-catenin pathway by inhibiting the proteasome. J. Biol. Chem. 2017, 292, 12503-12515. [CrossRef] [PubMed]

57. Cox, J.; Mann, M. MaxQuant enables high peptide identification rates, individualized p.p.b.-range mass accuracies and proteomewide protein quantification. Nat. Biotechnol. 2008, 26, 1367-1372. [CrossRef] 